\title{
Gastric hyperplastic polyps inversely associated with current Helicobacter pylori infection
}

\author{
XINJUAN YU ${ }^{1}$, ZHENGQIANG WANG $^{2}$, LILI WANG $^{1}$, XINYING MENG $^{3}$, CHANGHONG ZHOU $^{3}$, \\ YONGNING XIN ${ }^{4}$, WEILI SUN ${ }^{1,4}$ and QUANJIANG DONG ${ }^{1,4}$ \\ ${ }^{1}$ Central Laboratories, ${ }^{2}$ Clinical Laboratory, Departments of ${ }^{3}$ Health Care and ${ }^{4}$ Gastroenterology, \\ Qingdao Municipal Hospital, Qingdao University, Qingdao, Shandong 266000, P.R. China
}

Received June 17, 2019; Accepted January 30, 2020

DOI: $10.3892 /$ etm.2020.8567

\begin{abstract}
The incidence of gastric hyperplastic polyps (HPs) has been on the rise in recent years. The contribution of Helicobacter pylori infection to this trend has remained to be elucidated. The present study aimed to explore the association between HPs and H. pylori in China, an area with a high infection rate of $H$. pylori. In order to study trends of HPs and $H$. pylori infection over the past decades, cases encountered from 2009 to 2018 were assessed and a total of 109,150 consecutive patients who underwent esophagogastroduodenoscopy at Qingdao Municipal Hospital (Qingdao, China) were enrolled. The incidence of HPs and the prevalence of $H$. pylori were determined and their correlation was explored. Gastric HPs were detected in 1,497 patients (1.6\%) who received gastric biopsies. The incidence of HPs exhibited a rising trend, with a $~ 4$-fold increase in the annual detection rate from 2009 to 2018. The prevalence of $H$. pylori infection was inversely associated with the prevalence of HPs (adjusted odds ratio, 0.66). The prevalence of $H$.pylori in the examined cohort decreased with time $(\mathrm{r}=-0.76, \mathrm{P}=0.011)$. The decreasing trend of $H$. pylori infection was negatively correlated with the rising trend of HPs ( $\mathrm{r}=-0.64, \mathrm{P}=0.048)$, further indicating an inverse association between them. The difference in the prevalence of HPs between $H$. pylori-negative and -positive patients increased with age $(\mathrm{r}=0.80, \mathrm{P}=0.018)$. The age-associated increase was slower in $H$. pylori-infected patients. The decline in $H$. pylori infection with time appeared to not be associated with the birth cohort effect, suggesting the decline was not caused by exposure to environmental factors during an early period of
\end{abstract}

Correspondence to: Dr Quanjiang Dong, Central Laboratories, Qingdao Municipal Hospital, Qingdao University, 5 Donghaizhong Road, Qingdao, Shandong 266000, P.R. China

E-mail: jiangacer@126.com

Abbreviations: HPs, hyperplastic polyps; FGPs, fundic gland polyps; APs, adenomatous polyps; IM, intestinal metaplasia; OR, odds ratio

Key words: hyperplastic polyps, Helicobacter pylori, birth cohort life. The present results indicated that the incidence of gastric HPs increased with the decline in H.pylori infection, demonstrating an inverse association between the occurrence of HPs and the infection.

\section{Introduction}

Epithelial gastric polyps are pathologies incidentally discovered during endoscopic examinations. The prevalence varies between 2 and $6 \%$ in all patients subjected to endoscopy involving the stomach (1). Over the past decades, the occurrence of gastric polyps has exhibited a rising trend and the distribution spectrum of different types of gastric polyps has been changed. Epithelial polyps of the stomach comprise three types, namely fundic gland polyps (FGPs), hyperplastic polyps (HPs) and adenomatous polyps (APs). FGPs exhibit a steep rise in their occurrence and are the most common type (2-5). Older age is associated with an increased risk of gastric polyps, whereas Helicobacter pylori infection is inversely associated with the disease (6).

Gastric HPs develop from hyperproliferation of foveolar cells. Histologically, HPs appear as hyperplastic foveolae, cystic gland dilation and a variable amount of inflammation in the stroma. HPs most frequently occur in the antrum and tend to be larger than other gastric polyps. Larger HPs may cause bleeding from the ulcerated surface or intermittent gastric outlet obstruction. They carry a low malignant potential.

H. pylori is a Gram-negative spiral microorganism that colonizes the mucosa of the human stomach, infecting more than half of the world population. Infection with this bacterium has been indicated to be a cause of peptic ulcer disease and stomach cancer (7). However, recent evidence suggests that chronic infection with $H$. pylori may be beneficial to the host by conferring protection against gastroesophageal diseases, asthma, other allergic disease manifestations and inflammatory bowel diseases (7). Treatment of $H$. pylori infection-associated diseases is a complex problem. The most widely recommended regimen is a triple therapy comprising one proton pump inhibitor (PPI) and two antibiotics (8).

The association of HPs with $H$. pylori infection remains controversial. An inverse association of HPs with current infection of the bacterium has been indicated in the US, an area with low prevalence of $H$. pylori $(2,6)$. In a retrospective 
study on a cohort of 741,351 patients in the United States, the prevalence of $H$. pylori was relatively low, which was determined to be $<14 \%$. The infected patients had a lower risk for HPs with an odds ratio of 0.55 (0.51-0.59) (6). The inverse association has been confirmed in another study performed in the US (2). Contrary to this result, it has been indicated that $H$. pylori eradication may lead to regression of HPs. Successful eradication of $H$. pylori resulted in a statistically significant increase in the clearance rate of HPs (9-11).

Clarifying the association of HPs with $H$. pylori infection is particularly relevant to clinical management. At present, the inverse association between HPs and $H$. pylori has been mainly reported in areas of low prevalence of $H$. pylori. Therefore, the present study aimed to explore the association in a large cohort in China, an area with a high infection rate of $H$. pylori $(12,13)$. In order to study the trends of HPs and H.pylori infection over the past decades, the study was limited to patients encountered between 2009 and 2018.

\section{Materials and methods}

Study setting. The present study was performed at the Endoscopy Center and the Physical Examination Center of Qingdao Municipal Hospital (Qingdao, China). Biopsies were interpreted by an experienced group of pathologists. Standardized histopathology criteria were used to diagnose the histopathological types of gastric polyps (14). The study was approved by the ethics committee of Qingdao Municipal Hospital (Qingdao, China). As the data were collected entirely by reviewing existing records, no direct contact with either patients or providers was involved and no personal information on the subjects was revealed in any form, and exemption from the requirement for informed consent from participants was granted.

Sources of data. A total of 109,150 consecutive patients undergoing esophagogastroduodenoscopy (EGD) from 1 January 2009 to 31 December 2018 at the Endoscopy Center of Qingdao Municipal Hospital (Qingdao, China) were enrolled. The records of patients who had gastric biopsies were reviewed. Data including inspection time, the patients' birth year, age and sex, information on polyps, intestinal metaplasia (IM) and H. pylori infection were analyzed. The H.pylori status was obtained using histopathological methods. During the same period, the records of 11,077 healthy individuals undergoing health checkups at the Physical Examination Center of Qingdao Municipal Hospital (Qingdao, China) were analyzed. Data including the patients' birth year and $H$. pylori infection were analyzed. The $H$. pylori status was obtained with the ${ }^{13} \mathrm{C}$ urea breath test (Shenzhen Zhonghe Headway Bio-Sci \& Tech Co., Ltd.).

Statistical analysis. Statistical analyses were performed using SPSS 18.0 (SPSS Inc.) and R 3.5.1. Pearson correlation analysis was used to determine the correlation between the prevalence of gastric polyps and $H$. pylori infection, the correlation between the prevalence of $H$. pylori and the examination year, and the correlation between the difference in the prevalence of HPs between $H$. pylori-negative and -positive patients and age. Logistic regression analysis was used to identify risk factors potentially associated with the presence of gastric polyps.
Effects of $H$. pylori and cofactors on gastric polyps were estimated by determining odds ratios (ORs) and 95\% CIs. One-way analysis of variance (ANOVA) and the Student-Newman-Keuls (SNK) test were used to compare the average ages of patients undergoing EGD who obtained $H$. pylori status between each calendar year. The Cochran-Armitage trend test was performed to estimate the trends in H.pylori infection in different groups of patients according to birth year range using the CATT package in $\mathrm{R} . \mathrm{P}<0.05$ (two-tailed) was considered to indicate statistical significance.

\section{Results}

Rising trend of HPs. Over a 10-year period, the clinical data of 109,150 patients undergoing EGD was available and histopathology data were obtained for 94,031 participants. A total of 1,497 HPs (1.6\%) were detected in the 94,031 participants. The annual detection rate of HPs increased gradually from 2009 to 2018, suggesting a rising trend of the lesions $(r=0.95$, $\mathrm{P}<0.001$; Fig. 1A). During this period, the prevalence of HPs exhibited a $\sim 4$-fold increase. In line with this, the prevalence of FGPs also exhibited a rising trend (Fig. 1A). The increase in the prevalence of HPs appeared to be slower compared with that in FGPs and its proportion among gastric polyps exhibited an obvious drop (Fig. 1B).

Identification of risk factors for HPs. To explore the association of potential risk factors with HPs, logistic regression analyses were performed. The results demonstrated that $H$. pylori infection was inversely associated with HPs. The risk for HPs was significantly decreased in H.pylori-positive patients compared that in $H$.pylori-negative patients (adjusted OR, 0.66; 95\% CI, 0.59-0.75; P<0.001; Table I). Female sex and older age were associated with an increased risk for HPs. However, the OR value of female sex for HPs was lower than that for FGPs. Contrarily, female sex was associated with a lower risk for APs, although the difference was not statistically significant. Older age was associated with a slightly higher, but statistically significant risk for HPs as well as the other types of polyps. IM was also inversely associated with HPs (Table I).

Univariate logistic regression analysis suggested that there was a positive association between $H$. pylori and IM (OR: 1.31, 95\%CI: 1.27-1.35, $\mathrm{P}<0.001$; Table SI).

Declining trend of $H$. pylori infection. Of the 109,150 participants who underwent EGD examination, 87,699 cases were assigned $H$. pylori status by histopathological methods. H. pylori was present in 29,059 (33.1\%) of the 87,699 participants. The prevalence of $H$. pylori infection decreased gradually from $35.8 \%$ in 2009 to $32.0 \%$ in 2018 ( $\mathrm{r}=-0.76$, $\mathrm{P}=0.011$; Fig. 2A). This suggested a declining trend of H. pylori infection over the past decade. One-way ANOVA and the SNK test indicated that there was no significant difference in the averages of age between calendar years of the past decade (range from 52.41 \pm 14.56 to $53.13 \pm 13.49$ age; $\mathrm{P}>0.05$; Table SII). Thus, the decline in the infection rate of $H$. pylori was not associated with age.

The potential effect of the birth year range on $H$. pylori prevalence was explored in the study population. The prevalence was higher in the 1960-1969, 1970-1979 and 1980-1989 
Table I. Associations between different types of gastric polyp and age, gender, H. pylori and IM.

A, HPs

\begin{tabular}{|c|c|c|c|c|c|c|}
\hline \multirow[b]{2}{*}{ Variable } & \multirow[b]{2}{*}{$\operatorname{Cases}^{\mathrm{a}}(\mathrm{n}=1,497)$} & \multirow[b]{2}{*}{ Controls $(n=90,110)$} & \multicolumn{2}{|c|}{ Univariate model } & \multicolumn{2}{|c|}{ Multivariate model } \\
\hline & & & OR $(95 \% \mathrm{CI})$ & $\mathrm{P}$-value & OR $(95 \% \mathrm{CI})$ & $\mathrm{P}$-value \\
\hline Average age & $57.5 \pm 11.9$ & $52.6 \pm 14.1$ & $1.03(1.02-1.03)$ & $<0.001$ & $1.03(1.03-1.04)$ & $<0.001$ \\
\hline Female sex & $914(61.1)$ & $43,710(48.5)$ & $1.66(1.50-1.85)$ & $<0.001$ & $1.52(1.36-1.69)$ & $<0.001$ \\
\hline H. pylori ${ }^{\mathrm{b}}$ & $324(22.7)$ & $28,497(34.0)$ & $0.57(0.50-0.65)$ & $<0.001$ & $0.66(0.59-0.75)$ & $<0.001$ \\
\hline IM & $314(21.0)$ & $27,079(30.1)$ & $0.62(0.55-0.70)$ & $<0.001$ & $0.51(0.45-0.58)$ & $<0.001$ \\
\hline
\end{tabular}

\section{B, FGPs}

\begin{tabular}{|c|c|c|c|c|c|c|}
\hline \multirow[b]{2}{*}{ Variable } & \multirow[b]{2}{*}{$\operatorname{Cases}^{\mathrm{a}}(\mathrm{n}=2,209)$} & \multirow[b]{2}{*}{ Controls $(n=90,110)$} & \multicolumn{2}{|c|}{ Univariate model } & \multicolumn{2}{|c|}{ Multivariate model } \\
\hline & & & OR $(95 \% \mathrm{CI})$ & $\mathrm{P}$-value & OR $(95 \% \mathrm{CI})$ & P-value \\
\hline Average age & $55.0 \pm 11.7$ & $52.6 \pm 14.1$ & $1.01(1.01-1.02)$ & $<0.001$ & $1.02(1.01-1.02)$ & $<0.001$ \\
\hline Female sex & $1,571(71.1)$ & $43,710(48.5)$ & $2.61(2.38-2.87)$ & $<0.001$ & $2.32(2.11-2.55)$ & $<0.001$ \\
\hline H. pylori ${ }^{\mathrm{b}}$ & $204(9.4)$ & $28,497(34.0)$ & $0.20(0.18-0.24)$ & $<0.001$ & $0.23(0.20-0.26)$ & $<0.001$ \\
\hline IM & $348(15.8)$ & $27,079(30.1)$ & $0.44(0.39-0.49)$ & $<0.001$ & $0.41(0.36-0.46)$ & $<0.001$ \\
\hline
\end{tabular}

C, APs

\begin{tabular}{|c|c|c|c|c|c|c|}
\hline \multirow[b]{2}{*}{ Variable } & \multirow[b]{2}{*}{$\operatorname{Cases}^{\mathrm{a}}(\mathrm{n}=35)$} & \multirow[b]{2}{*}{ Controls $(\mathrm{n}=90,110)$} & \multicolumn{2}{|c|}{ Univariate model } & \multicolumn{2}{|c|}{ Multivariate model } \\
\hline & & & OR $(95 \% \mathrm{CI})$ & P-value & OR $(95 \% \mathrm{CI})$ & P-value \\
\hline Average age & $60.6 \pm 12.7$ & $52.6 \pm 14.1$ & $1.04(1.02-1.07)$ & 0.001 & $1.04(1.01-1.08)$ & 0.004 \\
\hline Female sex & $16(45.7)$ & $43,710(48.5)$ & $0.89(0.46-1.74)$ & 0.741 & $0.79(0.37-1.70)$ & 0.550 \\
\hline H. pylori ${ }^{\mathrm{b}}$ & $3(11.1)$ & $28,497(34.0)$ & $0.24(0.07-0.81)$ & 0.021 & $0.29(0.09-0.96)$ & 0.042 \\
\hline IM & $9(25.7)$ & $27,079(30.1)$ & $0.81(0.38-1.72)$ & 0.577 & $0.88(0.39-1.98)$ & 0.761 \\
\hline
\end{tabular}

${ }^{\text {aExcluded: }} 13$ juvenile polyps, 4 inflammatory fibroid polyps, 104 mixed polyps (including 95 HPs mixed with FGPs, 5 HPs mixed with APs, 2 FGPs mixed with APs, 1 HPs mixed with inflammatory fibroid polyps and 1 FGPs mixed with juvenile polyps), 59 with histological type not

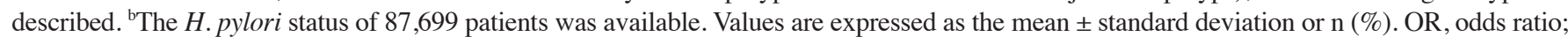
HPs, hyperplastic polyps; FGPs, fundic gland polyps; APs, adenomatous polyps; IM, intestinal metaplasia; H. pylori, Helicobacter pylori.
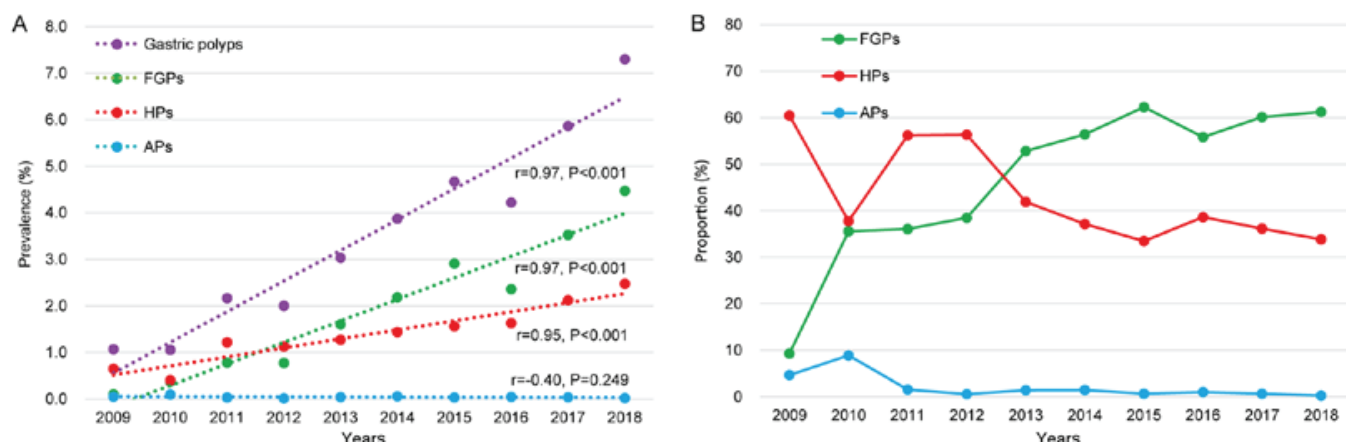

Figure 1. Changes in (A) the prevalence and (B) proportion of gastric polyps from 2009 to 2018. HPs, hyperplastic polyps; FGPs, fundic gland polyps; APs, adenomatous polyps.

birth cohorts, but lower in the cohorts born prior to 1960 and after 1989. Thus, there was no indication that the birth year in the population subjected to EGD examinations affected the prevalence of $H$. pylori (Fig. 2B). By contrast, a birth cohort 


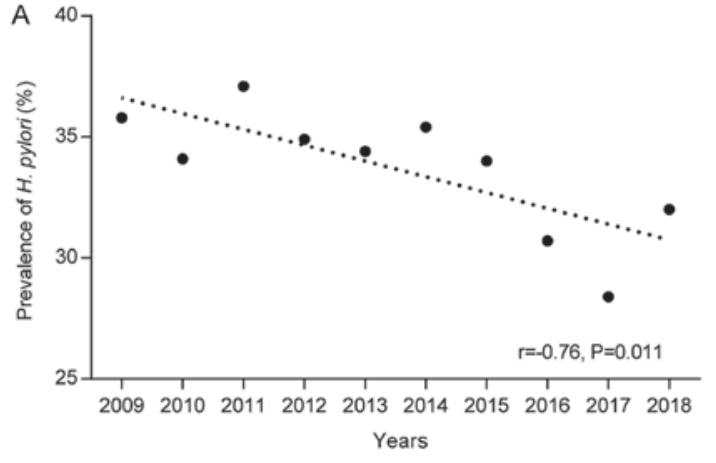

B
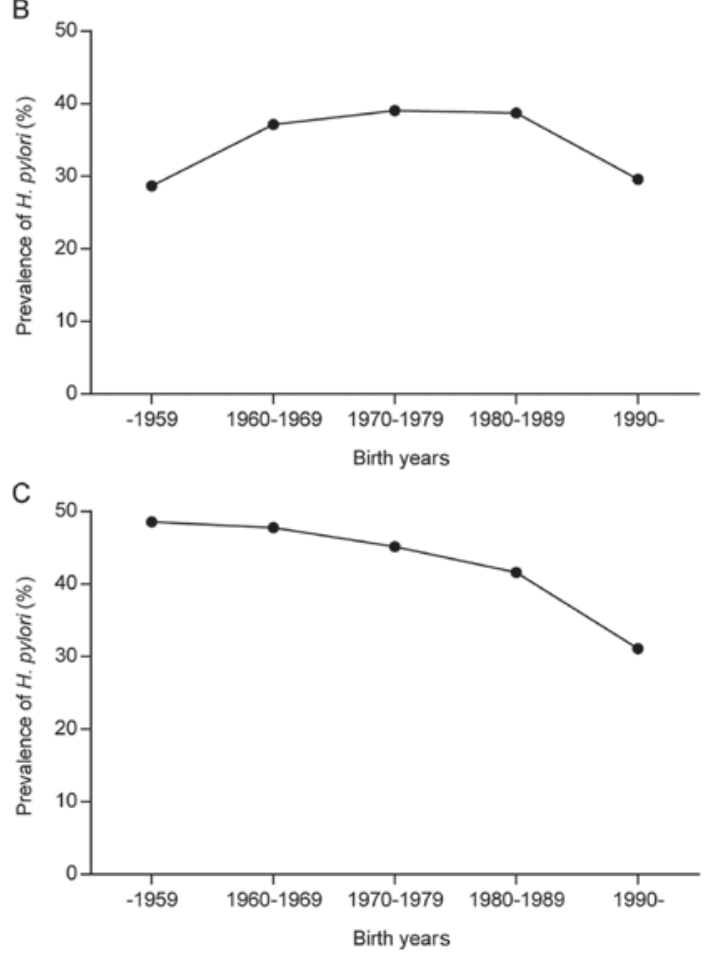

Figure 2. Trends in the prevalence of H. pylori with time. (A) Changes of the $H$. pylori-positive rate in each calendar year. (B) Effect of the birth year range on the $H$. pylori prevalence in patients undergoing esophagogastroduodenoscopy. (C) Effect of the birth year range on the H. pylori prevalence in individuals undergoing health checkups. H. pylori, Helicobacter pylori.

effect was detected in the population comprised of 11,007 individuals subjected to routine health checkups. The prevalence of $H$. pylori exhibited an apparent trend of decline from older to younger birth cohorts (P-value for trend, <0.001; Fig. 2C). The prevalence was $48.6 \%$ in the group born prior to 1960 and decreased gradually to $31.1 \%$ in the group born after 1989 .

Inverse association between the annual prevalence of H.pylori and HPS. Correlation analyses indicated that the annual prevalence of HPs increased with the decrease in the prevalence of $H$. pylori, suggesting an inverse association between them ( $\mathrm{r}=-0.64, \mathrm{P}=0.048$; Fig. 3A). An inverse association was also observed between the annual prevalence of $H$. pylori and gastric polyps or FGPs (Fig. 3B and C). However, the prevalence of $H$. pylori was not correlated with APs (Fig. 3D).

Impact of age on the effect of $H$. pylori infection on HPs. The prevalence of HPs exhibited an age-associated increase in $H$. pylori-negative and -positive groups (Fig. 4A), consistent with the aforementioned result that older age was a risk factor for HPs. However, it appeared that the age-associated increase was different between the two groups. Specifically, the age-associated rise in the prevalence of HPs was slower in H. pylori-infected patients. Correlation analysis revealed that the difference in the prevalence of HPs between the two groups increased with age $(r=0.80, P=0.018$; Fig. 4B).

\section{Discussion}

In the present study, an increase over time in the prevalence of HPs was identified. The reason may have, in part, been the improvement of detection techniques, but overall, it made less impact. To date, only few studies have explored the trend of the occurrence of HPs over several years. A study on a small population of 3,887 participants examined the prevalence of HPs at five time-points from 1980 to 2016 (5). They obtained no significant change in the occurrence of HPs. The present results indicated that the increase in the prevalence of HPs over time was slower compared with that of FGPs. Over the 10-year period, HPs changed from the dominant type of gastric polyps to the second-most common type due to the sharp rise in the prevalence of FGPs. This is in agreement with the results of earlier studies $(2-5,15)$.

The present results revealed that females have an increased risk for HPs. This is in contrast to studies from other geographical regions, according to which gender has no significant influence on the risk of HPs $(6,16)$, although females having a significant increase in the risk of gastric polyps has also been described in Western populations (17). These conflicting results may be attributed to the differences in ethnicity or differences in the prevalence of $H$. pylori $(18,19)$. In agreement with other studies, older age appeared to be associated with an increased risk for HPs $(6,7,20)$.

HPs carry a low but definite risk for malignant transformation. Thus, determining the association of H.pylori with HPs is a major clinical concern. Studies on large cohorts from areas of low prevalence of $H$. pylori demonstrated that the pathogen is inversely associated with the occurrence of HPs $(2,6)$. The present study, performed on a population of China, which had a high prevalence of $H$. pylori, provided similar results. Furthermore, the present data demonstrated that the prevalence of $H$. pylori exhibited a gradual decrease over the 10 -year period assessed. The annual prevalence of $H$. pylori in the population examined was inversely associated the detection rate of HPs. These results provide further evidence for the inverse association between $H$. pylori infection and HPs.

The possible reasons for the negative association between the infection and HPs remain controversial. It has been suggested that the increased prevalence of HPs is caused by IM of gastric mucosa, rather than the decreased prevalence of the infection (2). The negative association between the infection and HPs may be an indirect result that merely reflects the loss of current infection of $H$. pylori in IM. However, this explanation was not supported by other studies (6) and the present result regarding IM being inversely associated with HPs. To further demonstrate the negative association between the infection and HPs, the association between the infection and IM was analyzed. The present results indicated that $H$. pylori infection was positively associated with IM. This is consistent with results from earlier 



Figure 3. Correlation between the trend of H. pylori infection and the prevalence of (A) HPs, (B) gastric polyps, (C) FGPs and (D) APs. HPs, hyperplastic polyps; FGPs, fundic gland polyps; APs, adenomatous polyps; H. pylori, Helicobacter pylori.
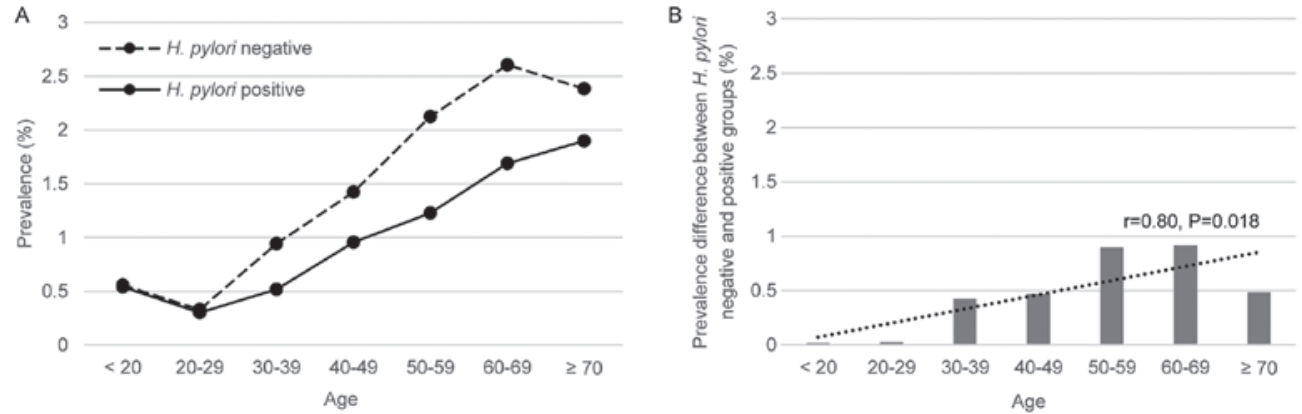

Figure 4. (A) Prevalence of hyperplastic polyps in H.pylori-negative and -positive subjects in different age groups (years) and (B) the prevalence difference. The difference increased with age. H. pylori, Helicobacter pylori.

studies, which examined the prevalence of the infection in IM in large cohorts $(21,22)$. Based on this information, H. pylori infection was indicated to be inversely associated with HPs.

In spite of being a pathogen causing a variety of gastric diseases, H. pylori infection provides protection from diarrhea, Barrett's esophagus, erosive esophagitis and gastroesophageal reflux disease (23-26). To explore whether the inverse association may indicate protection from HPs by H. pylori, the impact of exposure time to the pathogen on the prevalence of HPs was then analyzed. Considering that $H$. pylori is usually acquired during childhood $(27,28)$, the age of the patients was used to roughly estimate the exposure time of $H$. pylori. The results indicated that in spite of the age-associated increase in the prevalence of HPs, the rise was much slower in the infected patients. This indicates that the increase in the exposure time to the infection may have a potential protective effect on HPs. In contrast to the present results, a study on 183 patients suggested that the positive rate of $H$. pylori infection was lower in the group with regression of HPs (29). These contrasting results may be attributed to complexity in the factors involved in the regression of gastric polyps, including the polyp size, which is a key determinant for the disappearance of polyps. Another study indicated that the recurrence of HPs was more frequent in $H$. pylori-persistent patients after endoscopic removal of polyps (30). However, the present study also indicated that the eradication of $H$. pylori does not prevent the recurrence of HPs. Therefore, further follow-up studies are required to clarify the association between $H$. pylori and HPs, taking into account the population size and factors involved in the regression of polyps.

In the present study, the possible causes of the annual decrease of the prevalence of $H$. pylori in the population subjected to EGD examination were further analyzed. The results suggested that the declining prevalence of $H$. pylori may not be attributed to the birth cohort effect, that mean the decline was not caused by 
exposure to environmental factors during early life. However, the presence of the birth cohort effect was demonstrated in the population of patients subjected to health checkups. Therefore, the declining trend in the prevalence of $H$. pylori over time probably attributes to the eradication interventions for those patients who underwent EGD examination, as the patients undergoing EGD exhibit a variety of symptoms, and the majority of the cases received PPI or $H$. pylori eradication therapy.

In addition to the potentially protective effect on HPs by H.pylori, the roles of the wide use of PPIs in the development of HPs should be considered. The present results indicated that the decline in the proportion of HPs was accompanied by a relative increase in FGPs. This is what is usually observed in developed countries where the prevalence of $H$. pylori infection is low and the use of PPI is high (2). Recent studies have indicated that HPs occur after long-term use of PPIs in patients without $H$. pylori infection $(31,32)$. PPIs may stimulate the secretion of gastrin, leading to hyper-gastrinaemia. This may cause hyper-proliferation of the gastric mucosa and promote the development of HPs $(31,32)$. Despite the lack of information on the history of PPI use in the study population, the present results indicate that it is plausible that the wide use of PPIs accounts for the decline in the HPs. Further study is indicated for clarifying the roles of PPIs in the development of HPs. In addition, it has been reported that the dysbiotic microbiota is associated with the development of nasal and intestinal polyps (33-36). The human stomach harbors a complex microbiota in the luminal cavity and mucosa. Dysbiosis of the gastric microbiota has been linked to the occurrence of gastric cancer (37). Although the microbiota has not been characterized in gastric polyps, it is probable that dysbiosis of the gastric microbiota is causative for HPs. Therefore, antibiotic treatments may restore the dysbiotic microbiota and result in regression of HPs (38). H. pylori infection has a huge impact on the gastric microbiota (39-41). It is possible that the pathogen provides indirect protection against HPs through influencing the microbiota.

The present study examined the prevalence of gastric polyps including HPs in patients who underwent EGD. All of the patients had complaints of upper gastrointestinal symptoms, rather than being asymptomatic. Thus, it should be noted that the prevalence of gastric polyps determined in the present study may not represent the actual incidence of gastric polyps in the general population. Further studies on the general population are indicated to confirm the potential protection of $H$. pylori on the occurrence of HPs.

In conclusion, the present data demonstrate the rising prevalence of HPs over time. An inverse association between HPs and $H$. pylori infection was identified. It appears that H. pylori may indirectly protect against HPs, however the risk factors and mechanisms associated with this protection require further study.

\section{Acknowledgements}

Not applicable.

\section{Funding}

No funding was received.

\section{Availability of data and materials}

All data generated or analyzed during this study are included in this published article.

\section{Authors' contributions}

$X Y$ and $Q D$ were involved in the conception of the present study. $\mathrm{XY}$ and $\mathrm{ZW}$ designed the present study. YX and QD supervised the present study. ZW, LW, XM, CZ and YX performed data collection and/or processing. XY, LW, XM, CZ, YX and WS performed the data analysis and/or interpretation. $\mathrm{XY}$ and $\mathrm{ZW}$ wrote the manuscript. QD critically reviewed the manuscript. All authors have read and approved the final version of the manuscript.

\section{Ethics approval and consent to participate}

The present study was approved by the Ethics Committee of Qingdao Municipal Hospital (Qingdao, China).

\section{Patient consent for publication}

Not applicable.

\section{Competing interests}

The authors declare that they have no competing interests.

\section{References}

1. Elhanafi S, Saadi M, Lou W, Mallawaarachchi I, Dwivedi A, Zuckerman M and Othman MO: Gastric polyps: Association with Helicobacter pylori status and the pathology of the surrounding mucosa, a cross sectional study. World J Gastrointest Endosc 7: 995-1002, 2015.

2. Carmack SW, Genta RM, Schuler CM and Saboorian MH: The current spectrum of gastric polyps: A 1-year national study of over 120,000 patients. Am J Gastroenterol 104: 1524-1532, 2009.

3. Fan NN, Yang J, Sun G, Lu ZS, Ling Hu EQ, Wang XD and Yang YS: Changes in the spectrum of gastric polyps in the Chinese population. World J Gastroenterol 21: 9758-9764, 2015.

4. Cao H, Wang B, Zhang Z, Zhang H and Qu R: Distribution trends of gastric polyps: An endoscopy database analysis of 24121 northern Chinese patients. J Gastroenterol Hepatol 27: 1175-1180, 2012.

5. Velázquez-Dohorn ME, López-Durand CF and Gamboa-Domínguez A: Changing trends in gastric polyps. Rev Invest Clin 70: 40-45, 2018.

6. Sonnenberg A and Genta RM: Prevalence of benign gastric polyps in a large pathology database. Dig Liver Dis 47: 164-169, 2015.

7. Kyburz A and Muller A: Helicobacter pylori and extragastric diseases. Curr Top Microbiol Immunol 400: 325-347, 2017.

8. O'Morain NR, Dore MP, O'Connor AJP, Gisbert JP and O'Morain CA: Treatment of Helicobacter pylori infection in 2018. Helicobacter 23 (Suppl 1): e12519, 2018.

9. Nam SY, Park BJ, Ryu KH and Nam JH: Effect of Helicobacter pylori infection and its eradication on the fate of gastric polyps. Eur J Gastroenterol Hepatol 28: 449-454, 2016.

10. Kume K, Hirakoba M, Murata I, Yoshikawa I and Otsuki M: Disappearance of both MALT lymphoma and hyperplastic polyps in the stomach after eradication of Helicobacter pylori. Am J Gastroenterol 96: 2796-2797, 2001.

11. Ji F, Wang ZW, Ning JW, Wang QY, Chen JY and Li YM: Effect of drug treatment on hyperplastic gastric polyps infected with Helicobacter pylori: A randomized, controlled trial. World J Gastroenterol 12: 1770-1773, 2006.

12. Xie $\mathrm{C}$ and Lu NH: Review: Clinical management of Helicobacter pylori infection in China. Helicobacter 20: 1-10, 2015. 
13. Yu X, Yang X, Yang T, Dong Q, Wang L and Feng L: Decreasing prevalence of Helicobacter pylori according to birth cohorts in urban China. Turk J Gastroenterol 28: 94-97, 2017.

14. Goddard AF, Badreldin R, Pritchard DM, Walker MM and Warren B; British Society of Gastroenterology: The management of gastric polyps. Gut 59: 1270-1276, 2010.

15. Peretz A, Fuchs T, Livovsky DM, Turvall E, Pappo O and Ackerman Z: The changing histological pattern of gastric polyps in an ethnically heterogeneous population. Scand J Gastroenterol 47: 907-913, 2012.

16. Stolte M, Sticht T, Eidt S, Ebert D and Finkenzeller G: Frequency, location, and age and sex distribution of various types of gastric polyp. Endoscopy 26: 659-665, 1994.

17. Dore MP, Pes GM, Rocchi C, Loria MF, Soro S and Bassotti G: Are gastric hyperplastic polyps an additional manifestation in celiac disease?: Results from a retrospective study. Medicine (Baltimore) 96: e5923, 2017.

18. Nagy P, Johansson S and Molloy-Bland M: Systematic review of time trends in the prevalence of Helicobacter pylori infection in China and the USA. Gut pathogens 8: 8, 2016.

19. Hooi JKY, Lai WY, Ng WK, Suen MMY, Underwood FE, Tanyingoh D, Malfertheiner P, Graham DY, Wong VWS Wu JCY, et al: Global prevalence of Helicobacter pylori infection: Systematic review and meta-analysis. Gastroenterology 153: 420-429, 2017.

20. Takeuchi C, Yamamichi N, Shimamoto T, Takahashi Y, Mitsushima $\mathrm{T}$ and Koike K: Gastric polyps diagnosed by double-contrast upper gastrointestinal barium X-ray radiography mostly arise from the Helicobacter pylori-negative stomach with low risk of gastric cancer in Japan. Gastric Cancer 20: 314-321, 2017.

21. Sonnenberg A, Lash RH and Genta RM: A national study of Helicobacter pylori infection in gastric biopsy specimens. Gastroenterology 139: 1894-1901.e2; quiz e12, 2010.

22. Jiang JX, Liu Q, Zhao B, Zhang HH, Sang HM, Djaleel SM, Zhang GX and Xu SF: Risk factors for intestinal metaplasia in a southeastern Chinese population: An analysis of 28,745 cases. J Cancer Res Clin Oncol 143: 409-418, 2017.

23. Rothenbacher D, Blaser MJ, Bode G and Brenner H: Inverse relationship between gastric colonization of Helicobacter pylori and diarrheal illnesses in children: Results of a population-based cross-sectional study. J Infect Dis 182: 1446-1449, 2000.

24. Cohen D, Shoham O, Orr N and Muhsen K: An inverse and independent association between Helicobacter pylori infection and the incidence of shigellosis and other diarrheal diseases. Clin Infect Dis 54: e35-e42, 2012.

25. Wang Z, Shaheen NJ, Whiteman DC, Anderson LA, Vaughan TL, Corley DA, El-Serag HB, Rubenstein JH and Thrift AP: Helicobacter pylori infection is associated with reduced risk of Barrett's esophagus: An analysis of the Barrett's and esophageal adenocarcinoma consortium. Am J Gastroenterol 113: 1148-1155, 2018.

26. Wu JC, Sung JJ, Ng EK, Go MY, Chan WB, Chan FK, Leung WK, Choi CL and Chung SC: Prevalence and distribution of Helicobacter pylori in gastroesophageal reflux disease: A study from the East. Am J Gastroenterol 94: 1790-1794, 1999.

27. Malaty HM, El-Kasabany A, Graham DY, Miller CC, Reddy SG, Srinivasan SR, Yamaoka Y and Berenson GS: Age at acquisition of Helicobacter pylori infection: A follow-up study from infancy to adulthood. Lancet 359: 931-935, 2002.
28. Breckan RK, Paulssen EJ, Asfeldt AM, Kvamme JM, Straume B and Florholmen J: The all-age prevalence of Helicobacter pylori infection and potential transmission routes. A population-based study. Helicobacter 21: 586-595, 2016

29. Nam SY, Park BJ, Ryu KH and Nam JH: Effect of Helicobacter pylori eradication on the regression of gastric polyps in national cancer screening program. Korean J Intern Med 33: 506-511, 2018.

30. Kang KH, Hwang SH, Kim D, Kim DH, Kim SY, Hyun JJ, Jung SW, Koo JS, Jung YK, Yim HJ and Lee SW: The effect of Helicobacter pylori infection on recurrence of gastric hyperplastic polyp after endoscopic removal. Korean J Gastroenterol 71: 213-218, 2018 (In Korean).

31. Miyamoto S, Kato M, Matsuda K, Abiko S, Tsuda M, Mizushima T, Yamamoto K, Ono S, Kudo T, Shimizu Y, et al: Gastric hyperplastic polyps associated with proton pump inhibitor use in a case without a history of Helicobacter pylori infection. Intern Med 56: 1825-1829, 2017.

32. Kinoshita S, Nishizawa T, Mori H and Kikuchi M: Haemorrhagic gastric hyperplastic polyps associated with long-term use of proton pump inhibitor in a case without Helicobacter pylori infection. J Clin Pharm Ther 44: 493, 2019.

33. Chalermwatanachai T, Vilchez-Vargas R, Holtappels G, Lacoere T, Jáuregui R, Kerckhof FM, Pieper DH, Van de Wiele T, Vaneechoutte M, Van Zele T and Bachert C: Chronic rhinosinusitis with nasal polyps is characterized by dysbacteriosis of the nasal microbiota. Sci Rep 8: 7926, 2018.

34. Mangifesta M, Mancabelli L, Milani C, Gaiani F, de'Angelis N, de'Angelis GL, van Sinderen D, Ventura M and Turroni F: Mucosal microbiota of intestinal polyps reveals putative biomarkers of colorectal cancer. Sci Rep 8: 13974, 2018.

35. Rezasoltani S, Asadzadeh Aghdaei H, Dabiri H, Akhavan Sepahi A, Modarressi MH and Nazemalhosseini Mojarad E: The association between fecal microbiota and different types of colorectal polyp as precursors of colorectal cancer. Microb Pathog 124: 244-249, 2018

36. Peters BA, Dominianni C, Shapiro JA, Church TR, Wu J, Miller G, Yuen E, Freiman H, Lustbader I, Salik J, et al: The gut microbiota in conventional and serrated precursors of colorectal cancer. Microbiome 4: 69, 2016.

37. Coker OO, Dai Z, Nie Y, Zhao G, Cao L, Nakatsu G, Wu WK, Wong SH, Chen Z, Sung JJY and Yu J: Mucosal microbiome dysbiosis in gastric carcinogenesis. Gut 67: 1024-1032, 2018.

38. Printz C: Long-term antibiotic use associated with cancer-causing polyps. Cancer 123: 2996-2997, 2017.

39. JoHJ,Kim J,Kim N, Park JH, Nam RH, Seok YJ,Kim YR, Kim JS, Kim JM, Kim JM, et al: Analysis of gastric microbiota by pyrosequencing: Minor role of bacteria other than Helicobacter pylori in the gastric carcinogenesis. Helicobacter 21: 364-374, 2016.

40. Li TH, Qin Y, Sham PC, Lau KS, Chu KM and Leung WK: Alterations in gastric microbiota after H. pylori eradication and in different histological stages of gastric carcinogenesis. Sci Rep 7: 44935, 2017.

41. Gantuya B,El-Serag HB, Matsumoto T, Ajami NJ, Oyuntsetseg K, Azzaya D, Uchida T and Yamaoka Y: Gastric microbiota in Helicobacter pylori-negative and -positive gastritis among high incidence of gastric cancer area. Cancers (Basel) 11: pii: E504, 2019. 